Tropical Journal of Pharmaceutical Research December 2015; 14 (12): 2307-2311

ISSN: $1596-5996$ (print); 1596-9827 (electronic)

(C) Pharmacotherapy Group, Faculty of Pharmacy, University of Benin, Benin City, 300001 Nigeria.

All rights reserved.

Available online at http://www.tjpr.org

Original Research Article

http://dx.doi.org/10.4314/tjpr.v14i12.22

\title{
Patients Comprehension of Pharmaceutical Package Inserts Information in Karachi, Pakistan
}

\author{
Najia Rahim ${ }^{1 *}$, Kiran Rafiq ${ }^{2}$, Wajiha Iffat ${ }^{1}$, Shagufta Nesar ${ }^{3}$ and Sadia Shakeel ${ }^{1}$ \\ ${ }^{1}$ Dow College of Pharmacy, Dow University of Health Sciences, ${ }^{2}$ Institute of Pharmacy, Jinnah Sindh Medical University, \\ ${ }^{3}$ Department of Pharmaceutics, Faculty of Pharmacy, University of Karachi, Karachi, Pakistan \\ ${ }^{\star}$ For correspondence: Email: najia.rahim@duhs.edu.pk; Tel: +923002117194
}

Revised accepted: 20 September 2015

\begin{abstract}
Purpose: To investigate the knowledge and attitude of outpatients regarding pharmaceutical package inserts (PPIs) in Karachi, Pakistan.

Methods: The study design was cross-sectional and conducted from August to December 2013. A previously validated questionnaire was adopted, modified and revalidated. Outpatients were asked to respond to the questionnaire.

Results: A total of 456 patients responded to the questionnaire. The patients $(n=226,49 \%)$ were found to be keen on reading inserts in their mother language. Among the study population, $24.1 \%(n=$ $110)$ of respondents faced problem in reading and $29.8 \%(n=136)$ in understanding inserts. There was general awareness of the essential components of package inserts and $78.3 \%(n=357)$ of patients opted for further improvement in PPIs of drugs available in Pakistan. Chi square test revealed that educational status of patients was significantly associated with all of the items of the questionnaire $(p<$ 0.05).

Conclusion: The current status of PPIs of drugs available in local markets in Pakistan does not satisfy the patients' criteria and, therefore, needs improvement. The findings of this study provide a direction necessary to overcome problems related to PPIs and hence promote safe and effective use of medicines.
\end{abstract}

Keywords: Patients, Pharmaceutical package inserts, Awareness, Patients, Safe use of medicines

Tropical Journal of Pharmaceutical Research is indexed by Science Citation Index (SciSearch), Scopus, International Pharmaceutical Abstract, Chemical Abstracts, Embase, Index Copernicus, EBSCO, African Index Medicus, JournalSeek, Journal Citation Reports/Science Edition, Directory of Open Access Journals (DOAJ), African Journal Online, Bioline International, Open-J-Gate and Pharmacy Abstracts

\section{INTRODUCTION}

Safety and efficacy of medicines accompanied with accurate and reliable drug product information. Pharmaceutical companies adopt various scientific ways to provide information including verbal communication through medical representatives, scientific meetings as well as written material (periodical, promotional materials, pharmaceutical packaging insert). Printed information accompanying drug products includes the information on the primary or immediate drug packaging, the external package as well as the inserts or leaflets [1].

The pharmaceutical package insert (PPI) is an important tool for providing essential drug information to patients taking over-the-counter (OTC) medicines. Studies have shown that the PPI helps to bridge the information gap between health care providers and patients and also boosts the level of patients' knowledge about medications [2]. It is very important that the information written on PPI should strictly follow the criteria as that it should be comprehensive, 
up to date, clear and legible for patients and care givers in case of OTC drugs.

The quality and quantity of information available in the PPI plays important role for influential patients' compliance and satisfaction [3]. The studies showed that patients who read the PPI are more likely to follow the instructions [4]. Despite the fact that physicians and pharmacists are the preferred sources of information, healthcare professionals do not always ensure optimal knowledge transfer [5]. In addition, information given verbally may likely be either misunderstood or forgotten that is why a paper label is given [6]. Researchers also revealed that medication error and poor patient compliance may be the consequences of problem in reading and understanding of PPI by patients [7-9].

It is imperative to know the perception of patients/consumers about PPI. Such type of information has not been reported from Pakistan yet. Although some studies regarding the detailed analysis of such PPIs was done [10,11]. The present study was aimed to determine the attitude and perception of the outpatients towards PPIs of pharmaceutical product marketed in Pakistan.

\section{EXPERIMENTAL}

\section{Study design and setting}

A questionnaire-based cross-sectional study was conducted over 5-month period (August to December 2013) in two out-patient department of one public and one private sector tertiary care hospitals of Karachi. Previously validated questionnaire was adopted and modified [12,13]. Internal reliability score was checked by applying cronbach's alpha. Patients attending outpatient clinics constituted the study population and asked to fill the questionnaire. The sample size was calculated by Open Epi® online software and non probability sampling technique was adopted.

There was no earlier estimation regarding the knowledge of PPIs in Pakistan. Therefore, it was assumed that the prevalence of knowledge was $50 \%$ and calculated the required sample for our survey with an allowable error of $5 \%$ and $95 \%$ confidence limits. Altogether, 456 respondents participated in the study. Written consents were taken and participation in the study was anonymous. Demographic data of respondents including age and educational status were also recorded.

\section{Statistical analysis}

Data was entered in Statistical Package for Social Sciences (SPSS 20.0, Chicago, IL). Descriptive statistics on characteristics of respondents were calculated. Response was calculated as number and frequency of YES or NO. Bivariate analysis was applied using Chi square test to observe the association of age and educational status with their responses $(p<$ 0.05).

\section{Ethical issues}

The study was conducted after taking approval from the director/head of outpatient department of tertiary care hospitals. Demographics and responses of the patients collected during the present study were kept confidential and only being used for this research paper. Patients were briefed about the purpose of the study prior to conduct the research.

\section{RESULTS}

The present plan comprising of questionnaire based study was executed to be acquainted with the perception of outpatients of Karachi about PPI. The adopted questionnaire was revalidated and cronbach's alpha of 15 items was 0.730 . Four hundred and fifty six respondents participated in the study (an overall response rate was $82.9 \%$ \%). The study population comprised of uneducated ( $n=26,5.7 \%$ ), O \& A grade $(\mathrm{n}=112,24.5 \%$ ) and graduated patients ( $n=318,69.8 \%$ ). Majority of the respondents were below the age of 30 years $(n=284,62.3$ $\%)$

The study outcomes revealed that $22.8 \%$ ( $n=$ 104) of patients do not read PPIs before using the medications. Respondents also had problems in reading $(\mathrm{n}=110,24.1 \%)$ and understanding ( $n=136,29.8 \%$ ) of PPI. The patients ( $n=226,49.6 \%$ ) were found to be keen in reading inserts in their mother language. Approximately $84 \%(n=383)$ emphasized that the information regarding dose, direction and duration of use, side effects, precautions and interactions were useful parts of PPIs of OTC medicines. A majority of respondents ( $n=357$, $78.3 \%)$ thought that the PPIs of products marketed in Pakistan need improvement to meet the international standards (Table 1).

Statistical analysis (Chi square test) disclosed that educational status of patients was significantly associated with all of the items of 
questionnaire $(p<0.05)$, however age of the patients was significantly associated $(p<0.001)$ with some of the responses i.e. easy to understand PPI, a toll free number in the package insert and manufacturer information is useful.

\section{DISCUSSION}

PPIs have influential role of providing essential medical information to improve patient compliance and minimize medication errors. Effective designing of PPIs should be focused on the literacy level of patients. Furthermore, presenting information in mother language of patient improves patient comprehension. This is very crucial regarding OTC medicines used by general public. A study conducted in Turkey said that $78.2 \%$ of patients read PPIs [8]. In Germany, a study revealed that only $54.8 \%$ of patients read PPIs always before using new medications [14]. However, in UK only $35 \%$ of patient reads PPI completely [9]. Another researcher reported that $49.2 \%$ patients always read $\mathrm{PPI}$ and $48.3 \%$ of patients said that they faced problem in understanding PPIs [15]. As majority of the respondents were educated, they were aware of the significance of reading PPI. A small proportion of respondents faced problems in reading and understanding PPIs (Table 1).

The information on PPIs should preferably be in the mother language for improved patient compliance. Otherwise, it will be very hard to understand PPIs by general population. A large number of respondents prefer to read PPIs in both languages, i.e., English and their mother language. However, half of the respondents wished to read these PPIs in their mother language i.e. Urdu. Palestine consumers of medications were also found willing to have PPIs in Arabic [16]. Medication error and adverse effects were observed in patients with limited literacy including misuse of drug and multiple medication regimens [7]. The reasons may include misunderstanding of PPIs leading to treatment failure which can be overcome by designing PPI in mother language.

PPI includes information regarding active drug ingredient, indication and contraindication. Majority of respondents opinioned positively to have these information on PPI. General public of Saudi Arabia emphasized on the importance of indications and adverse drug reactions mentioned on PPIs [17]. FDA published guidelines for the consumer medication information in written form emphasize on the basic information written on the PPIs including some other consideration. These include certain general information, including encouraging patients to communicate with healthcare professionals and disclaimer statements; information that is scientifically accurate, unbiased and up-to-date and information in an understandable and legible format that is readily comprehensible to consumer [18].

Table 1: Outpatients' response to the 15-item questionnaire

\begin{tabular}{lcc}
\hline Question & Yes & No \\
\cline { 2 - 3 } & $\mathbf{N}(\%)$ & $\mathbf{N}(\%)$ \\
\hline Do you read package insert? & $352(77.2)$ & $104(22.8)$ \\
Do you read expiry date before using the medication? & $418(91.7)$ & $38(8.3)$ \\
Do you store the medication at the temperature specified in the package insert? & $342(75)$ & $114(25)$ \\
Do you prefer to read package insert in English? & $334(72.2)$ & $122(28.8)$ \\
Do you prefer to read package insert in Urdu? & $226(49.6)$ & $230(50.4)$ \\
Do you prefer to read package insert in both English and Urdu? & $299(65.6)$ & $157(34.4)$ \\
Do you think that written information of package insert is easy to read? & $346(75.9)$ & $110(24.1)$ \\
Do you think that written information of package insert is easy to understand? & $320(70.2)$ & $136(29.8)$ \\
Do you think that a toll free number in the package insert to give any required drug & $312(68.4)$ & $144(31.6)$ \\
information can be useful? & $357(78.3)$ & $99(21.7)$ \\
Do you think that information on package insert should be improved in our country? & $370(81.1)$ & $86(18.9)$ \\
Do you think that Active ingredient, clinical indication and contraindications are & \\
useful part of package insert for you? & $383(84)$ & $73(16)$ \\
Do you think that dosage instructions and direction for use are useful part of & $386(84.6)$ & $70(15.3)$ \\
package insert for you? & \\
Do you think that side effects, precautions and interactions are useful part of & $318(69.7)$ & $138(30.3)$ \\
package insert for you? & & \\
Do you think that manufacturers' information is useful part of package insert for & $352(77.2)$ & $104(22.8)$ \\
you? & &
\end{tabular}


It was very encouraging that the patients, who were educated, had knowledge of gold standards for PPIs.

Many studies reported a link between reading, understanding the PPIs and patient characteristics including literacy, health status, occupation and age $[19,20]$. Bivariate analysis using chi-square test was applied to observe the association of age and educational status of patients with their response. Educational status of the respondents was significantly associated with their response to all of questions $(p<0.05)$. Age of the patients was also significantly associated $(p<0.001)$ with some of the responses i.e. easy to understand PPI, a toll free number in the package insert and manufacturer information is useful. Other researchers also observed such type of association [7].

The study results showed that PPIs should be improved in terms of readability and understanding keeping in view the patient demographics especially literacy level and age group. It is a general perception of our community that multinational companies are much better than local companies. In this continuation a question was asked regarding the comparison of package inserts of multinational companies with local companies? Majority of patients answered in 'Yes' (Table 1). They also drew the attention towards the need for improvement PPls of products marketed in Pakistan. Ministry of Health is also responsible to regulate PPIs by implementing the standard rules to communicate properly all the information to the patients as well as to the health care professional irrespective of the type of manufacture.

\section{Limitation of the study}

The first limitation is that the sample size used was small. Secondly, patients with little or no literacy level were in a minority. The present survey was conducted among outpatients in Karachi and, therefore, the results should not be generalized to the entire nation of Pakistan.

\section{CONCLUSION}

The objective of catching the perception of outpatients' about PPI was accomplished. It revealed that the information written on PPI of drugs available in local market of Pakistan was readable and understandable for the literate patients. They were not observed fully satisfied with current status of PPIs.

\section{REFERENCES}

1. Shivkar $Y$. Clinical information in drug package inserts in India. J Postgrad Med 2009; 55(2).

2. Mottram D. Comparative evaluation of patient information leaflets by pharmacists, doctors and the general public. J Clin Pharm Ther 1997; 22(2): 127-134.

3. Gibbs $S$, Waters $W$, George C. Prescription information leaflets: a national survey. JRSM Open 1990; 83(5): 292-297.

4. Weitbrecht $W$, Voßkämper C. Influence of the drug package information paper on compliance of neurological and psychiatric outpatients. Fortschr Neurol Psychiat 2002; 70(4): 178-184.

5. Dougherty L, Stuttaford J. Patient education. Turning over a new leaflet. Nurs Times 1993; 89(45): 46.

6. Winfield $A$, Owen $C$. Information leaflets: a means of improving patient compliance. $\mathrm{Br} J$ Pharm Pract 1990; 12: 206-209.

7. Davis TC, Wolf MS, Bass PF, Thompson JA, Tilson $\mathrm{HH}$, Neuberger $M$, Parker RM. Literacy and misunderstanding prescription drug labels. Ann Intern Med 2006; 145(12): 887-894.

8. Berry DC, Knapp $P$, Raynor $D$. Provision of information about drug side-effects to patients. Lancet 2002; 359(9309): 853-854.

9. Pander $\mathrm{MH}$, Lentz L. Improving the usability of patient information leaflets. Patient Educ Couns 2010; 80(1): 113-119.

10. Rizvi M, Khan N, Tanwir S. Int J Pharma Neutra Res 2014; 1(1): 13-17.

11. Rahim N, Rafiq K. Judgement of Pharmaceutical Package Insert Available in Pakistan from Local and Multinational Companies. AJPHS 2013; 3(1): 597600.

12. Fuchs J, Hippius M, Schaefer M. Analysis of German package inserts. Int J Clin Pharmacol Ther 2006; 44(1).

13. Raynor D, Svarstad B, Knapp P, Aslani P, Rogers MB, Koo M, Krass I, Silcock J. Consumer medication information in the United States, Europe, and Australia: A comparative evaluation. J Am Pharm Assoc 2007; 47(6): 717-724.

14. Fuchs J, Hippius M. Inappropriate dosage instructions in package inserts. Patient Educ Counsel 2007; 67(1): 157-168.

15. Nathan JP, Zerilli T, Cicero LA, Rosenberg JM. Patients' use and perception of medication information leaflets. Ann Pharmacother 2007; 41(5): 777-782.

16. Rowa'Al-Ramahi ANZ, Na'em-Kettana WS. Attitudes of consumers and healthcare professionals towards the patient package inserts-a study in Palestine. Pharm Pract 2012; 10(1): 57.

17. Bawazir SA, Abou-Auda HS, Gubara OA, Al-Khamis KI, Al-Yamani MJ. Public attitude toward drug technical package inserts in Saudi Arabia. J Pharm Technol 2003; 19(3): 209-218. 
18. Guidance on Useful Written Consumer Medication Information (CMI). Center for Drug Evaluation and Research, Food and Drug Administration, MD, USA, 2006.

19. Koo M, Krass I and Aslani P. Enhancing patient education about medicines: factors influencing reading and seeking of written medicine information. Health Expect 2006; 9(2): 174-187.

20. Miller MJ, Schmitt MR, Allison JJ, Cobaugh DJ, Ray MN and Saag KG. The role of health literacy and written medicine information in nonsteroidal antiinflammatory drug risk awareness. Ann. Pharmacother.2010; 44(2): 274-284. 